\title{
TELESEISMIC BODY WAVE INVERSION
}

\author{
Moshou A. ${ }^{1}$, Papadimitriou P. ${ }^{1}$, and Makropoulos K. ${ }^{1}$ \\ ${ }^{1}$ National and Kapodistrian University of Athens, Faculty of Geology and Geoenvironment, \\ Department of Geophysics - Geothermicsamoshou@geol.uoa.gr,ppapadim@geol.uoa.gr, \\ kmacrop@geol.uoa.gr
}

\begin{abstract}
Body wave inversion methodology is developed to determine the earthquake source parameters in teleseismic distances. The generalized inversion technique, based on the singular value decomposition method, is applied to determine the deviatoric moment tensor which is decomposed in two parts. The first one is related to the pure Double Couple $(D C)$ and the second one to the compensated linear vector dipoles (CLVD). The best solution of the overdetermined problem is obtained by minimizing the misfit between observed and synthetic seismograms. The proposed methodology is applied for the four strongest earthquakes that occurred recently in Greece (20012006).
\end{abstract}

Key words: focal mechanism, moment tensor inversion, body waves.

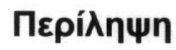

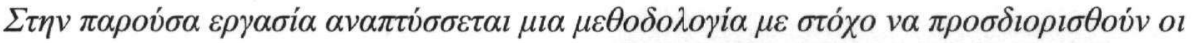

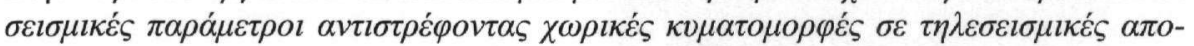

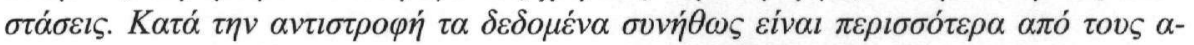

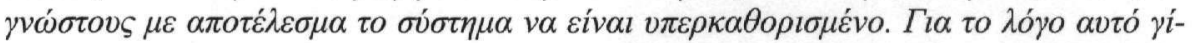

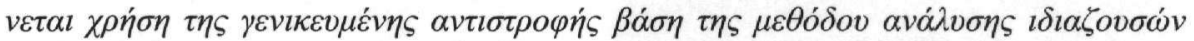

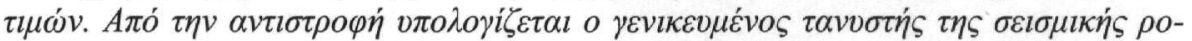

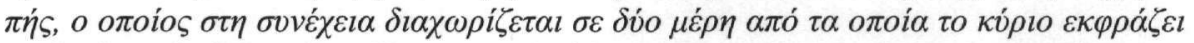

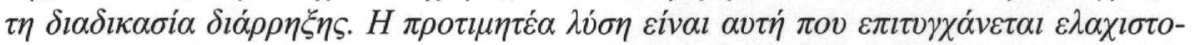

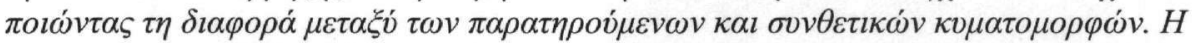

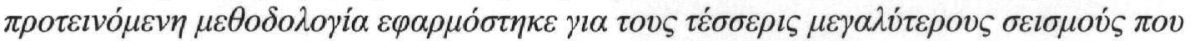

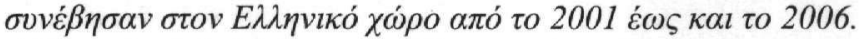

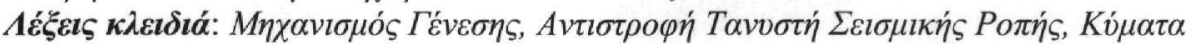
$\chi \omega ́ p o v$.

\section{Introduction}

The study of the rupture process is important to understand the source properties of an earthquake. The moment tensor, as a mathematical description of equivalent forces and moments in a point source, is used to study the source processes. The source mechanism can be decomposed into basic models of fracture mechanics, using eigenvalue analysis (Jost and Hermann 1989). A complete inversion implies knowledge of the moment tensor components, the depth and the source time function of the event (Aki and Richards 1980). 
Eigenvalue and eigenvector analysis of the moment tensor can be used to determine the components of the moment tensor. In the case where the sum of the eigenvalues vanishes, the moment tensor has only deviatoric components. Furthermore, if one eigenvalue is equal to zero the deviatoric moment tensor represents a pure double couple. On the other hand, if no eigenvalue vanishes and their sum still equals zero, the moment tensor can be decomposed into a double couple (DC) and a compensated linear vector dipole (CLVD). In general, a complete moment tensor is the superposition of the two vector dipoles (DC and CLVD) and an isotropic component (Lay and Wallace 1995). In the case of an earthquake the isotropic part is zero.

Different methods are developed both in time (Kanamori 1972, Langston and Helmberger 1975, Madariaga and Papadimitriou 1985, Hartzell and Heaton 1983, Nabelek 1984, Papadimitriou 1988 ) and in frequency domain (Brune 1970, Oncescu 1986). Langston and Barker $(1981,1982)$ developed a generalized inverse technique based on the moment tensor formalism. Teleseismic body wave inversion methodology was proposed by Kikuchi and Kanamori (1982, 1986 and 1991). In the first paper a numerical method is developed in order to study complex body waves into a multiple shock sequence. Assuming that the events have identical fault geometry and depth, the far field source time function is obtained as a superposition of ramp functions. In the next paper they considered a general case where the rupture process consists of sub events with arbitrary source parameters. In the third paper they developed a method to determine the mechanism and the rupture process considering that the main fault consists of a set of sub faults, each of which could have different focal mechanism.

Taking into account the previous studies, a methodology is developed in order to calculate the source parameters of an earthquake. For this purpose Green's functions are calculated for five elementary types of faulting. The linear combination of these Green's functions produces synthetic seismograms that can directly be compared to the corresponding observed ones. The moment tensor elements are calculated using the SVD method. Finally, the best solution is obtained by minimizing the differen between observed and synthetics. In the last part of the present work the proposed methodology applied for the four strongest earthquakes that occurred recently in Greece.

\section{Moment tensor representation}

The description of the physics of seismic sources is of major research interest in seismology. The seismic sources can be represented by equivalent forces, producing displacements on the earth's surface, identical to those created during the physical process at the source. The displacement at the free surface can be expressed as a sum of moment tensor elements times the corresponding Green's function. The displacement field $u_{n}(x, t)$ using the representation theorem (Aki and Richards 1980) can be calculated at a position $\mathrm{x}$ and time $\mathrm{t}$ by the following relation:

$u_{n}(x, t)=\int_{-\infty}^{\infty} d \tau \iint\left[u_{\Sigma}(\xi, \tau)\right] \cdot c_{i j k l} n_{j} \frac{\partial G_{n k}(x, t-\tau ; \xi, 0)}{\partial \xi_{l}} d \Sigma$

where $\mathrm{u}_{\mathrm{i}}(\xi, \tau)$ is the definition of dislocation, $\mathrm{G}_{\mathrm{nk}, \mathrm{l}}(\mathrm{x}, \mathrm{t} ; \xi, \tau)$ is the partial derivative of Green's tensor expressing the nth component of the displacement response at point $\mathbf{x}$ to a point dislocation in the kth direction on a plane normal to the 1 direction at position $\xi$. $\Sigma$ is the fault plane surface, $\mathrm{n}_{\mathrm{j}}$ is the jth component of $\mathbf{n}$ which is the vector normal to $\Sigma$. $c_{i j k l}$ is the elastic constant tensor of Hooke law, $\left[\mathrm{u}_{\mathrm{i}}(\xi, \tau)\right] \mathrm{c}_{\mathrm{ijk}}$ is the moment density tensor. Taking the derivative with respect to the $\tau$, the following relation is obtained:

$u_{n}(x, t)=\iint_{\Sigma}\left[u_{i}(\xi, \tau)\right] \cdot c_{i j k l} \cdot n_{j} * G_{n k, l} d \Sigma$

Considering the moment density tensor $\mathrm{m}_{\mathrm{k} 1}$ : 


$$
m_{k l} \equiv\left[u_{i}(\xi, \tau)\right] \cdot \eta_{j} \cdot c_{i j k l}
$$

the equation (2) becomes:

$$
u_{n}(x, t)=\iint_{\Sigma} m_{k l} * G_{n k, l} d \Sigma
$$

The integration of the moment density tensor $\mathrm{m}_{\mathrm{kl}}$ on $\Sigma$ defines the moment tensor $\mathrm{M}_{\mathrm{kl}}$

$$
\mathrm{M}_{k l}=\iint_{\Sigma} m_{k l} \cdot d \Sigma
$$

Combining the relations (4), (5) the displacement field can be written:

$$
u_{n}(x, t)=M_{k l} * G_{n k, l}
$$

The last equation indicates that the displacement in a position $\mathrm{x}$ and time $\mathrm{t}$ is defined as a convolution between the moment tensor $\mathrm{M}_{\mathrm{kl}}$ and the partial derivative of Green's tensor. Furthermore, a synthetic seismogram can be calculated at a specific geographical position using the following equation:

$$
\operatorname{syn}_{i}(t)=\frac{1}{4 \pi \rho c^{3}} \cdot \frac{g(\Delta, h)}{r_{0}} \cdot R_{i} \cdot \dot{\mathrm{M}}\left(t-\frac{r}{c}\right)
$$

where $g(\Delta, h)$ is the geometric spreading, $r_{0}$ is the radius of the earth, $\rho$ is the density at the source, $\mathrm{R}$ denotes the radiation pattern in case of $\mathrm{P}, \mathrm{SH}$ and $\mathrm{SV}$-waves $(\mathrm{i}=1,2,3)$ respectively, $\mathrm{c}$ denotes the $\mathrm{v}_{\mathrm{P}}$ ( $\mathrm{P}$ waves) or $\mathrm{v}_{\mathrm{S}}(\mathrm{S}$ waves) velocity and $\mathrm{M}$ is the moment rate. The moment tensor is represented by a $3 \times 3$ symmetric matrix. Using a set of data which consists of synthetics and the corresponding observed ones, it is possible to construct a nx6 matrix and, by applying the Generalised Inverse Method, to calculate the source parameters of the event.

\section{Inverse Problem}

The displacement observations $d_{i}$ can be defined as the sum of a discrete model specified by a finite number of parameters $\mathbf{m}_{\mathbf{j}}$, and the Green's functions $\mathrm{G}_{\mathrm{ij}}$ :

$$
d_{i}=\sum_{j=1}^{M} G_{i j} m_{j} \quad(i=1,2, \ldots, N, \mathrm{j}=1,2, \ldots, \mathrm{M})
$$

This can be written as:

$$
d=G \cdot m
$$

where $d$ is a vector that contains the observed displacements for each station, $G$ is the matrix with columns that are the Green's functions and $\mathbf{m}$ is a vector containing the moment tensor elements (Meju 1994). More details for the algorithm can be found in Langston et al. (1982). Concerning the problems considered in the present study, it is assumed that a large number of measurements have been made and that the solution of the inversion problem is over-determined (Menke 1984). In order to solve the equation (9) the inverse matrix $\left(G^{T} G\right)^{-1}$ must be calculated. Different methods can be used, like the Singular Value Decomposition (SVD) or normal equations. Lanczos (1950) found that any matrix $\mathrm{G}$ could be decomposed as:

$$
G=U S V^{T}
$$

where $U$ is an orthogonal matrix which consists of the eigenvectors associated with the nonzero eigenvalues of the square matrix $\mathrm{GG}^{\mathrm{T}}, \mathrm{S}$ is the diagonal matrix of positive square roots of the non 
zero eigenvalues of the square matrix $\mathrm{GG}^{\mathrm{T}}$, which are called singular values of $\mathrm{G}$, and $\mathrm{V}^{\mathrm{T}}$ is an orthogonal matrix which consists of the eigenvectors of the square matrix $G^{T} G$. Then, the model can be calculated by the following formula:

$m=\left(G^{T} G\right)^{-1} G^{T} d=G^{-1} \cdot d$

$\mathrm{G}^{-1}$ is the generalized inverse of $\mathrm{G}$ and the equation (10) becomes:

$$
m=V S^{-1} U^{\mathrm{T}} d
$$

The last equation indicates that the model can be determined by calculating the eigenvectors and eigenvalues of the $\mathrm{V}$ and $\mathrm{U}$ matrices. In this study the Singular Value Decomposition method (SVD) was used. The obtained eigenvectors are parallel to the principal stress axes and the norm of the matrix is equal to the seismic moment. In general, a moment tensor $\mathrm{M}_{\mathrm{kl}}$ is symmetric and has 6 independent elements $\left(a_{m}, m=1,6\right)$. In case of an earthquake the trace must be equal to zero (no isotropic part). The determinant of the matrix must also be equal to zero:

$$
\left.\begin{array}{l}
\operatorname{Trace}\left[\mathrm{M}_{k l}\right]=0 \\
\operatorname{Det}\left[\mathrm{M}_{k l}\right]=0
\end{array}\right\} \text {. }
$$

Considering the two mentioned constraints, the obtained moment tensor consists of 5 independent elements. Kikuchi and Kanamori (1991) defined that the moment tensor can be decomposed in 5 elementary moment tensors:

$$
\mathbf{M}_{k l}^{1}=\left[\begin{array}{lll}
0 & 1 & 0 \\
1 & 0 & 0 \\
0 & 0 & 0
\end{array}\right], \mathbf{M}_{k l}^{2}=\left[\begin{array}{ccc}
1 & 0 & 0 \\
0 & -1 & 0 \\
0 & 0 & 0
\end{array}\right], \mathbf{M}_{k l}^{3}=\left[\begin{array}{lll}
0 & 0 & 0 \\
0 & 0 & 1 \\
0 & 1 & 0
\end{array}\right], \mathbf{M}_{k l}^{4}=\left[\begin{array}{lll}
0 & 0 & 1 \\
0 & 0 & 0 \\
1 & 0 & 0
\end{array}\right], \mathbf{M}_{k l}^{5}=\left[\begin{array}{ccc}
-1 & 0 & 0 \\
0 & 0 & 0 \\
0 & 0 & 1
\end{array}\right]
$$

In this case the moment tensor $\mathrm{M}_{\mathrm{kl}}$ can be calculated by the linear combination of the 5 elementary moment tensors mentioned above (Fukushima et al. 1989):

$$
\mathrm{M}_{k l}=\sum_{m=1}^{5} a_{m} \cdot \mathbf{M}_{k l}^{m}
$$

and using the coefficient $\mathrm{a}_{\mathrm{m}}$ the above relation becomes (Kikuchi and Kanamori 1991):

$$
\mathrm{M}_{k l}=\left[\begin{array}{ccc}
\alpha_{2}-\alpha_{5}+\alpha_{6} & \alpha_{1} & \alpha_{4} \\
\alpha_{1} & -\alpha_{2}+\alpha_{6} & \alpha_{3} \\
\alpha_{4} & \alpha_{3} & \alpha_{5}+\alpha_{6}
\end{array}\right]
$$

where $a_{6}=0$ (isotropic part). In summary, by creating five elementary Green functions it is possible to calculate a synthetic seismogram directly compared to the observed one. Following, the coefficients $\mathrm{a}_{\mathrm{m}}$ are calculated, whereas the moment tensor $\mathrm{M}_{\mathrm{kl}}$ can be calculated using the last equation. The model parameters are estimated by minimizing the difference between observed and synthetics using the least square method:

$$
\Delta=\sum_{i=1}^{n} w_{i} \int\left[o b s_{i}(t)-\operatorname{syn} n_{i}(t)\right]^{2} d t=\min
$$

where $\mathrm{w}_{\mathrm{i}}$ is the weight for each station and $\mathrm{n}$ is the number of observations. The best solution is obtained by minimizing the equation (17). 


\section{Applications}

The proposed methodology was applied to the largest earthquakes that occurred recently in Greece. The first two applications concern the 2001 Skyros and the 2003 Lefkada earthquakes (shallow events), while the last two concern the 2002 Karpathos and the 2006 Kythira earthquakes (deep events). These events occurred in different seismotectonic settings, fact that permits us to evaluate the reliability of the method. The employed waveforms consist of $\mathrm{P}, \mathrm{SV}$ and SH phases recorded by stations of the Global Seismograph Network (GSN). A sampling frequency of $4 \mathrm{~Hz}$ was used for all data recorded at epicentral distances ranging from $30^{\circ}$ to $90^{\circ}$. The instrument's response was deconvolved, then integrated to displacement and convolved with a band pass filter. Synthetic seismograms were generated for a point source buried in a half space using, for the shallow events, density $2.7 \mathrm{~g} / \mathrm{cm}^{3}, v_{P}=6.5 \mathrm{~km} / \mathrm{sec}$ and $\mathrm{v}_{S}=3.6 \mathrm{~km} / \mathrm{sec}$ for $\mathrm{P}$ and $\mathrm{S}$ waves, respectively. In addition the attenuation effect is taken into account using Futterman's (1962) operator with $t^{*}=1$ for $\mathrm{P}$ and $\mathrm{t}^{*}=4$ for $\mathrm{SH}$ and SV waves. The source parameters of the selected earthquakes are calculated by minimizing the misfit between observed and synthetic seismograms, using the proposed methodology. Following, the results of the application of the selected events are presented.

\subsection{The $M_{w}=6.52001$ Skyros Earthquake}

On July 26, 2001 (00:21 GMT) an earthquake of Magnitude Mw=6.5 occurred close to the Northwest coast of Skyros Island causing some damage, landslides and rockfalls. The epicenter $\left(39.03^{\circ} \mathrm{N}, 24.27^{\circ} \mathrm{E}\right)$ is located at the end of the Southern branch of the North Anatolian Fault (NAF). The North Aegean is dominated by the North Anatolian Fault, characterised by dextral strike slip type faulting and divided in several branches. Along these different branches of NAF large earthquakes occurred the last 50 years, like the event on February 191968 near the Agios Efstratios Island, on January 181982 near the Thassos Island and on August 61983 near the Lemnos Island. Finally, the nearest and largest earthquake occurred on March 41967 which is characterised by normal type faulting (Papadimitriou, 1988). The focal mechanism of the Skyros event indicates strike slip faulting (Benetatos et al. 2002, Papadopoulos et al. 2002). To determine the source parameters of this earthquake body wave inversion modelling is applied using the proposed methodology. Broadband digital data were selected, recorded at teleseismic distances between $30^{\circ}-90^{\circ}$ degrees with a good signal to noise ratio. Synthetic waveforms were generated using a simple trapezoidal source time function of $7 \mathrm{sec}$ duration, in order to determine the components of the moment tensor and the focal depth of the mainshock. The result of the inversion was a focal mechanism indicating strike slip type faulting at a depth of $14 \mathrm{~km}$. The determined fault plane solution is: $\varphi=160^{\circ}, \delta=65^{\circ}$ and $\lambda=7^{\circ}$, while the seismic moment was found equal to 6 $10^{25} \mathrm{dyn} \cdot \mathrm{cm}$. The result of this procedure is presented in figure 1.

\subsection{The $M_{w}=6.32003$ Lefkada Earthquake}

On 14 August $2003\left(05: 14\right.$ GMT) an earthquake of magnitude $\mathrm{M}_{\mathrm{W}}=6.3$ occurred close to the NW coast of Lefkada Island causing some damage, landslides and ground fissures, mainly at the northern part of the island. The epicenter $\left(38.86^{\circ} \mathrm{N}, 20.56^{\circ} \mathrm{E}\right)$ is located at the northern part of the Kefallinia-Lefkada dextral transform fault zone which forms the transition zone between the Hellenic subduction zone to the south and the collision zone to the north (Papadimitriou et al. 2006). The area was affected by numerous earthquakes since the antiquity (Papazachos and Papazachou 2002). Most of these events were located close to the recent one, producing damages with the same characteristics (landslides, rockfalls, liquefaction effect, ground fissures). The focal mechanism of this event indicates strike slip faulting along the NE-SW direction (Papadopoulos et al. 2003, Zahradnik et al. 2005, Benetatos et al. 2005) and is in agreement with the general type faulting of the area (Anderson and Jackson 1987, Papadimitriou 1988, Louvari et al. 1999). As a first step, synthetic waves were generated using a simple trapezoidal source time function, in order to determine the components of the moment tensor and the focal depth of the mainshock. The source parameters of the Lefkada earthquake were calculated using as total source duration 6 sec. 


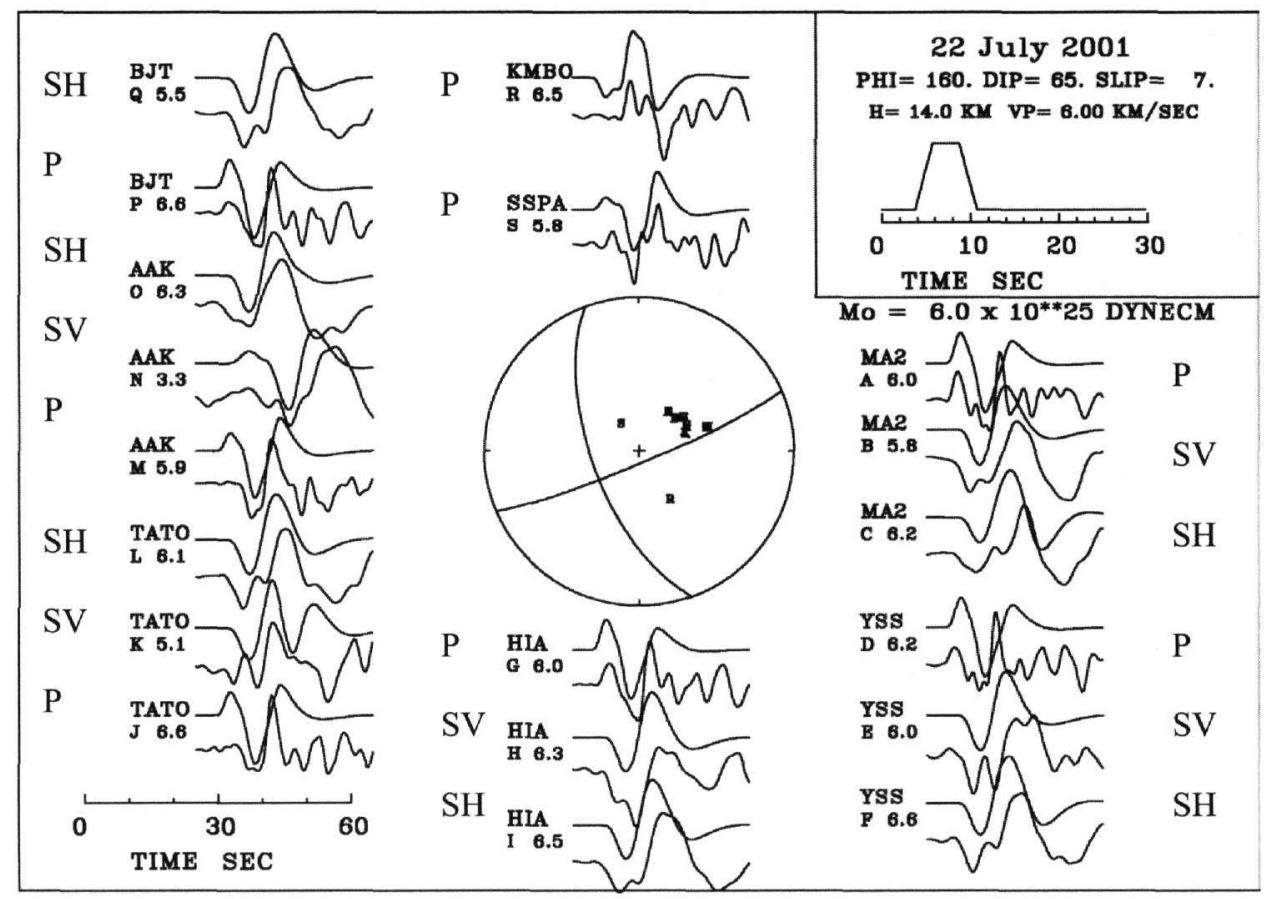

Figure 1 - Body wave modeling of the 2001 Skyros earthquake

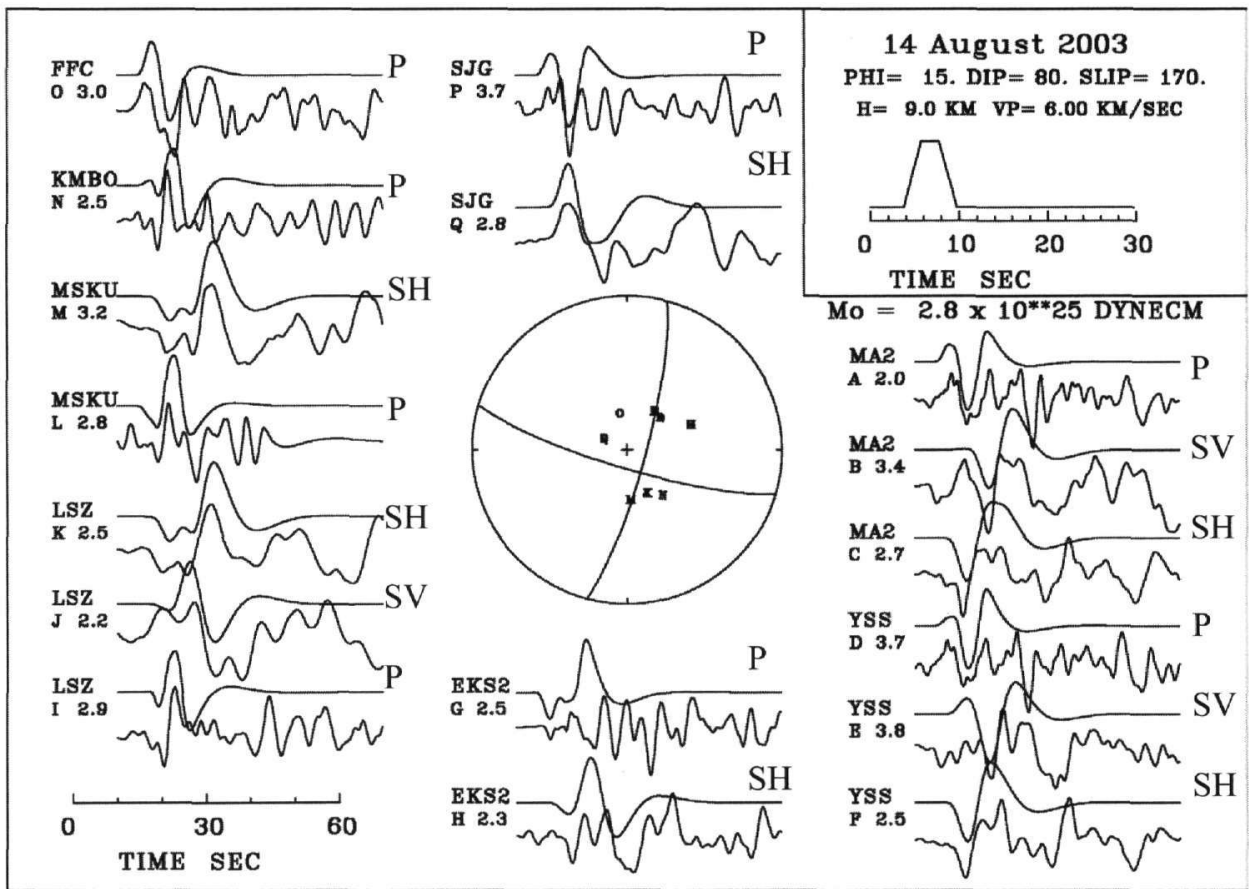

Figure 2 - Body wave modeling of the 2003 Lefkada earthquake 
Body wave inversion revealed strike slip type faulting. The best fit solution is: $\varphi=15^{\circ}, \delta=80^{\circ}$ and $\lambda$ $=170^{\circ}$, while the focal depth is $9 \mathrm{~km}$ and the seismic moment $2.810^{25} \mathrm{dyn} \cdot \mathrm{cm}$ (Fig. 2), in agreement to the results obtained by Benetatos et al. (2005) and by Papadimitriou et al. (2006). Papadimitriou et al. (2006) used a complex source time function for the Lefkada earthquake. In the present study this procedure was not followed, since the main objective was to retrieve the depth and the focal mechanism of the event.

\subsection{The $M_{w}=6.2$ Karpathos Earthquake}

On 22 January 2002 (04:53 GMT) an earthquake of Magnitude $M_{w}=6.3$ occurred west of the Karpathos Island (Southern Greece), where no damages are imported. The hypocenter $\left(35.56^{\circ} \mathrm{N}\right.$, $26.73^{\circ} \mathrm{E}, \mathrm{H}=90 \mathrm{~km}$ ) is located on the Hellenic subduction zone. The area is characterized by several deep events that occurred in the past, but this is the first instrumentally recorded deep event in the area. The main event was followed by a small number of aftershocks. A simple trapezoidal source time function with duration of $6 \mathrm{sec}$ was applied to calculate the focal mechanism and the depth of the main event. The inversion process resulted strike slip type faulting at a depth of $90 \mathrm{~km}$. The best fit fault plane solution is: $\varphi=95^{\circ}, \delta=89^{\circ}$ and $\lambda=50^{\circ}$ with seismic moment equal to 2.6 $10^{25} \mathrm{dyn} \cdot \mathrm{cm}$ (Fig. 3). The result obtained by the inversion shows a good fit between the observed and the synthetic waves, indicating that the source time function is not complex. Furthermore, the deep $\mathrm{pP}$ and sP phases are evident and well-modeled.

\subsection{The $M_{w}=6.7$ Kythira Earthquake}

On 8 January 2006 (13:34 GMT) an earthquake of Magnitude $\mathrm{M}_{\mathrm{w}}=6.7$ occurred close to the Northeast cost of Kythira Island (Southern Greece) causing some damages landslides and rockfalls. The hypocenter $\left(36.21^{\circ} \mathrm{N}, 23.40^{\circ} \mathrm{E}, \mathrm{H}=65 \mathrm{Km}\right)$ is located on the Hellenic subduction zone which characterizes the Southern part of Greece. This event is one of the largest earthquakes, after the event of 1903, which occurred in the same area. Previous works indicate the existence of a seismic gap in this region (Wyss and Baer 1981). The main event was followed by a small number of aftershocks, with maximum magnitude $\mathrm{M}_{\mathrm{w}}=5.5$. The major part of the seismic activity in this region is related to the active subduction zone along the Hellenic Arc, as well as the backarc area. Consequently, the area presents complex deformation, where the southern part of the Aegean region is moving towards the southwest at approximately $40 \mathrm{~mm} / \mathrm{yr}$ (Kahle et al. 1996). The area is characterized by active faulting with an almost vertical orientation in relation to the subduction zone. The components of the moment tensor and the focal depth of the mainshock were determined using a simple trapezoidal source time function with duration of $7 \mathrm{sec}$. Thrust type faulting was revealed after applying body wave inversion. The obtained focal mechanism is $\varphi=205^{\circ}, \delta=45^{\circ}$ and $\lambda=55^{\circ}$, the seismic moment $8.410^{25} \mathrm{dyn} \cdot \mathrm{cm}$, while the focal depth was equal to $65 \mathrm{~km}$ (figure 4). The evident and well-constrained deep pP and sP phases show that the focal depth is well determined. The obtained focal mechanism is in agreement with the one proposed by the Harvard CMT solution.

\section{Conclusions}

The source parameter determination of an earthquake can be obtained using a moment tensor inversion method. For this purpose, Green functions can be generated for five elementary type faulting. The linear combination of these Green functions can produce synthetics that can directly be compared to the corresponding observed ones. The components of the seismic moment tensor were determined, using the generalized inverse technique based on the SVD method. The proposed methodology was applied to the recently largest events that occurred in Greece using teleseismic broad-band digital data between $30^{\circ}$ and $90^{\circ}$. The obtained results are generally compared with those obtained by other methods. In addition, using $\mathrm{P}, \mathrm{SH}$ and $\mathrm{SV}$ body waves with a good signal/noise ratio, accurate source parameters are obtained, even in the case that few stations are taken into account. 


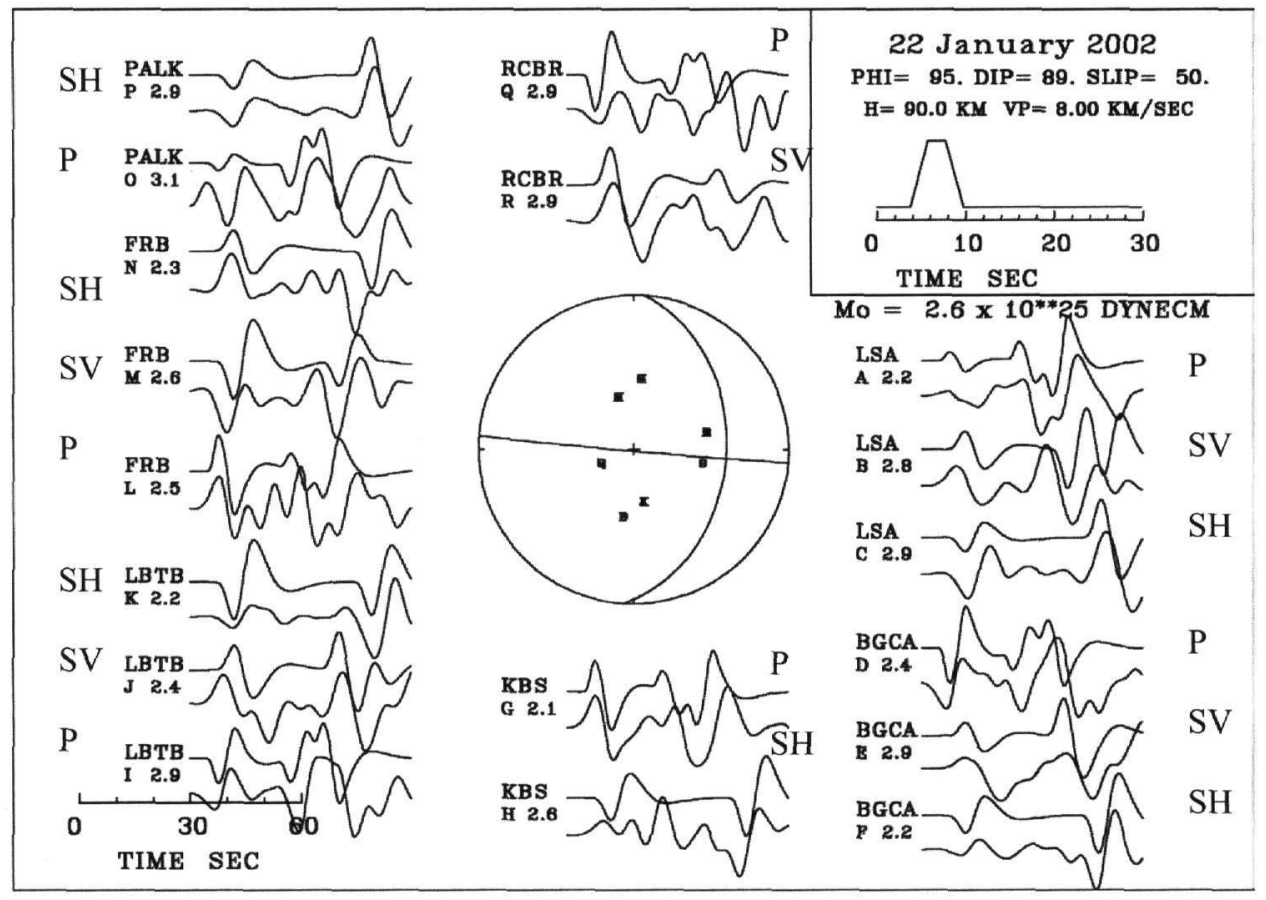

Figure 3 - Body wave modeling of the 2002 Karpathos earthquake

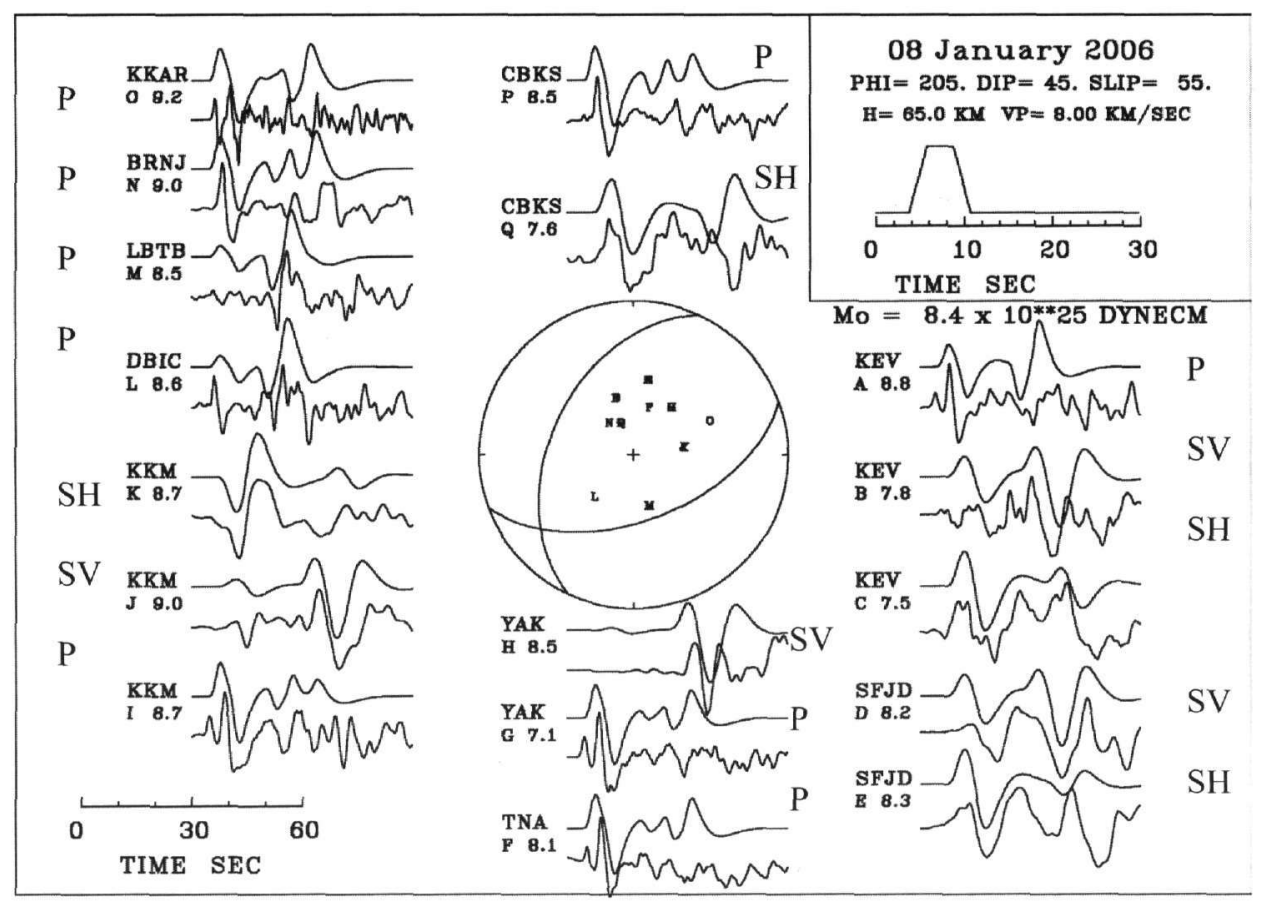

Figure 4 - Body wave modeling of the 2006 Kythira earthquake 
The methodology that was developed in this study is applied to the four largest events that occurred recently in Greece. Concerning the 2001 Skyros and the 2003 Lefkada shallow events, they indicate strike slip type faulting. On the other hand, the seismic parameters of the 2002 Karpathos and 2006 Kythira events revealed reverse focal mechanism at depths equal to $90 \mathrm{~km}$ and $65 \mathrm{~km}$, respectively. It is the first time that modeling can be applied for large events occurring at these depths in the Southern Aegean. These events are located on the subduction zone that characterizes the region.

\section{References}

Aki and Richards P.G., 1980. Quantitative Seismology, W.H. Freeman, San Fransisco, 1, 55.

Anderson, H., and Jackson, J., 1987. Active tectonics of the Adriatic region, Geophys. J. $R$. Astron. Soc., 91, 937-983.

Benetatos, C., Roumelioti, Z., Kiratzi, A., and Melis, N., 2002. Source parameters of the M 6.5 Skyros Island (North Aegean Sea) earthquake of July 26, 2001, Annali di Geofisica, 45, 513-526.

Benetatos, C., Kiratzi, A., Roumelioti, Z., Stavrakakis, G., Drakatos, G., and Latoussakis, I., 2005. The 14 Augoust 2003 Lefkada Island (Greece) earthquake: Focal mechanisms of the mainshock and of the aftershocksequence, Journal of Seismology, 9, 171-190.

Brune, J., 1970. Tectonic stress and spectra of seismic shear waves, J. Geophys. Res., 75, 49975002.

Fukushima, T., Suetsugu, D., Nakanishi, I., and Yamada, I., 1989. Moment tensor inversion for near earthquake using long - period digital seismogram, J. Phys.Earth, 37, 1 - 29.

Futtermann, W., 1962. Dispersive body waves, J. Geophys. Res. 67, 5279-5291.

Hartzell, S., and Heaton, T., 1983. Inversion of strong ground motion and teleseismic waveform data for the fault rupture history of the 1979 Imperial Valley, California earthquake, Bull.Seism.Soc Am., 76, 649-674.

Jost, M., and Hermann, R., 1989. A student's Guide to and Review of Moment Tensors, Seismological Research Letters, 60 (2), 37 - 57.

Kahle, H.-G., Muller, M.V., and Veis, G., 1996. Trajectories of crustal deformation of western Greece from GPS observations 1989-1994, Geophys. Res. Lett., 23 (6), 667-680.

Kanamori, H., 1972. Determination of effective tectonic stress associated with earthquake faulting, the Tottori earthquake of 1943, Phys. Earth. Planet. Interiors, 5, 426-434.

Kikuchi, M., and Kanamori, H., 1982. Inversion of complex body waves, Bull. Seism. Soc. Am., $72,491-506$

Kikuchi, M., and Kanamori, H., 1986. Inversion of complex body waves II, Phys. Earth Planet. Interiors, 43, $205-222$.

Kikuchi, M., and Kanamori, H., 1991. Inversion of complex body waves - III, Bull. Seism. Soc. Am., 81(6), 2335 - 2350.

Lanczos, C., 1950. An iteration method for the solution of the eigenvalues problem of linear differential operators, J. Res. N. B. S., 45, 255-282.

Langston, C., and Helmberger, D., 1975. A procedure of modelling shallow dislocation sources, Geophysics, J. R. Astr. Soc., 42, 117-130. 
Langston, C., 1981. Source Inversion of seismic waveforms: The Koyna, India, earthquakes of 13/09/1967, Bull. Seism.Soc. Am., 71 (1), 1 - 24.

Langston, C., Barker, J., and Pavlin, G., 1982. Point - source inversion techniques, Physics of the Earth and Planetary Interiors, 30, 228 - 241.

Lay, T., and Wallace, T., 1995. Modern Global Seismology, Press, New York.

Louvari, E., Kiratzi, A., and Papazachos, B., 1999. The Cephalonia transform fault and its continuation to western Lefkada Island, Tectonophysics, 308, 223-236.

Madariaga, R., and Papadimitriou, P., 1985. Gaussian beam modeling of upper mantle phases, Annales Geophysicae 3, 6, 799-812.

Meju, M., 1994. Geophysical Data Analysis: Understanding Inverse Problem Theory and Practise, Course Notes Series, Volume 6, S.N. Domenico.

Menke, W., 1984. Geophysical Data Analysis, Discrete Inverse Theory, Academic, San Diego, CA

Nabelek, J., 1984. Determination of Earthquake source parameters from inversion of body waves, PhD Thesis, MIT.

Papadimitriou, P., 1988. Etude de la structure du manteau superieur de l' Europe et modelisation des ondes de volume engendrees par des seismes egeens, Doctorat de l' Universite Paris VII, Paris France.

Papadimitriou, P., Kaviris, G., and Makropoulos, K., 2006. The $\mathrm{M}_{\mathrm{w}}=6.3$ Lefkada earthquake (Greece) and induced stress transfer changes, Tectonophysics, 423, 73-82.

Papadopoulos, G., Ganas, A., and Plessa, A., 2002. The Skyros earthquake $\left(\mathrm{M}_{\mathrm{w}} 6.5\right)$ of 26 July 2001 and precursory seismicity patterns in the North Aegean Sea, Bull. Seism. Soc. Am., 92, 312-322.

Papadopoulos, G., Karastathis, V., Ganas, A., Pavlides, S., Fokaefs, A., and Orfanogiannaki, K., 2003. The Lefkada Ionian Sea (Greece), shock $\left(M_{w}\right.$ 6.2) of 14 Augoust 2003: Evidence for the characteristic earthquake from seismicity and ground failures, Earth Planets Space, 55, 713-718.

Papazachos, B., and Papazachou, C., 2002. The earthquakes of Greece, Ziti Publ. Thessaloniki, Greece.

Zahradnik, J., Serpetsidaki, A., Sokos, E., and Tselentis, G., 2005. Iterative deconvolution of regional waveforms and a double-event interpretation of the 2003 Lefkada earthquake, Greece, Bull. Seismol. Soc. A., 95, 159-172.

Wyss, M., and Baer, M., Earthquake hazard in the Hellenic arc. In D.W. Simpson and P. G. Richards (eds), Earthquake prediction, Maurice Ewing Series, vol. 4, 153-172pp., Amer. Geophys. Union, 1981. 